\title{
The Effects of Control Mechanisms on Complementors' Behavioral Intentions: An Empirical Study of Reward-Based Crowdfunding Platforms
}

\author{
Evgheni Croitor \\ Technical University of Darmstadt \\ croitor@ise.tu-darmstadt.de
}

\author{
Dominick Werner \\ Technical University of Darmstadt \\ werner@ise.tu-darmstadt.de
}

\author{
Alexander Benlian \\ Technical University of Darmstadt \\ benlian@ise.tu-darmstadt.de
}

\begin{abstract}
Although Information Systems research has been increasingly exploring the role of control mechanisms on digital platforms, empirical research on the effects of control mechanisms on complementors' behavioral intentions in platform ecosystems is sparse. Control mechanisms refer to measures employed by platform providers to influence desirable behaviors of complementors and thus to manage dynamics, growth, and evolution of their digital platforms. Drawing on IS control literature and goal attainment theory, we conducted an online survey with 116 complementors from two major reward-based crowdfunding platforms, Kickstarter and Indiegogo. Our findings reveal that input control (self control) decreases (increases) complementors' intention to stay on their respective digital platform. Furthermore, we shed light on the role of complementors' perceived effort, perceived usefulness and satisfaction in shaping these relationships. Thus, our findings contribute to the literature on digital platforms in general and control mechanisms in particular.
\end{abstract}

\section{Introduction}

Digital platforms and their corresponding ecosystems have fundamentally changed the way products and services are created, distributed, and consumed [11]. Platform providers deliberately open up their ecosystems and enable complementors to provide complements to their digital platforms, thereby increasing platforms' diversity and innovation $[15,20]$. For example, the overall number of projects submitted on Kickstarter and Indiegogo has increased from 270,000 to over $1,200,000$ between 2013 and 2019 [29, 30].

As digital platforms and their number of complementors and complements grow, platform providers need to apply control mechanisms (i.e., input, behavioral, output, clan and self control) to align their interests and strategies with those of the complementors [56]. In particular, two control mechanisms are becoming increasingly important for platform providers: input control and self control. Input control can be described as the set of mechanisms used by the platform provider that screen and sort out complementors and their complements before entering the digital platform's ecosystem [13]. Consider, for example, the input control on the Kickstarter platform: project creators must verify their identity and provide proof that their business is registered in the respective country. Furthermore, all projects must comply with platform provider-set rules and policies, thereby limiting the scope of projects allowed to be submitted [31]. Self control, on the other hand, occurs when platform providers encourage complementors to exercise self-regulation by providing tools for selfmanagement and by structuring the platform environment appropriately [40]. For example, to reinforce project creators' self-regulation, Indiegogo provides several tools which support project creators in project management, marketing, PR, and post campaign strategies.

Researchers have repeatedly investigated the effects of control mechanisms on digital platforms [12, $13,21-24,48,49,54$ ] (an overview of these studies is presented in Table 1). However, prior IS research on control mechanisms exhibits four particularly noteworthy shortcomings. First, although prior IS control research acknowledges the importance of investigating different control mechanisms in combination $[10,23,33]$, particularly the effects of the increasingly important input control on digital platforms were thus far only investigated in isolation. Second, our understanding is incomplete as to why the effects of input and self control unfold and how perceived effort, perceived usefulness and satisfaction shape these relationships. Third, the extent literature on complementors' behavioral intentions focuses primarily on the effects of control mechanisms on complementors' continuance intention (e.g., [12, 13, 23]), but neglected to investigate complementors' switching intention, which is an equally important factor for platforms' success and sustainability [50]. Lastly, 
previous studies on control mechanisms in the context of crowdfunding platforms (e.g., [48, 54]) focused on the overall success of projects and thus, comprehensive insights from complementors' perspective are still missing.

Table 1. Prior studies of control mechanisms on digital platforms.

\begin{tabular}{|c|c|c|c|c|c|}
\hline \multirow[t]{2}{*}{ Authors } & \multicolumn{5}{|c|}{ Control Mechanisms } \\
\hline & 引 & 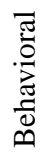 & 壳 & 胥 & $\stackrel{ \pm}{\infty}$ \\
\hline $\begin{array}{l}\text { Goldbach et al. } \\
\text { (2014) [24] }\end{array}$ & - & $\mathrm{X}$ & $\mathrm{X}$ & - & $\mathrm{X}$ \\
\hline $\begin{array}{l}\text { Goldbach et al. } \\
(2015)[21]\end{array}$ & - & - & - & $\mathrm{X}$ & - \\
\hline $\begin{array}{l}\text { Goldbach et al. } \\
(2015)[22]\end{array}$ & - & - & - & $\mathrm{X}$ & $\mathrm{X}$ \\
\hline $\begin{array}{l}\text { Tiwana (2015) } \\
\text { [49] }\end{array}$ & $\mathrm{X}$ & - & - & - & - \\
\hline $\begin{array}{l}\text { Wessel et al. } \\
\text { (2017) [54] }\end{array}$ & $X$ & - & - & - & - \\
\hline $\begin{array}{l}\text { Goldbach et al. } \\
\text { (2018) [23] }\end{array}$ & - & $\mathrm{X}$ & $\mathrm{X}$ & - & $\mathrm{X}$ \\
\hline $\begin{array}{l}\text { Thies et al. } \\
\text { (2018) [48] }\end{array}$ & $X$ & - & - & - & - \\
\hline $\begin{array}{l}\text { Croitor \& Benlian } \\
\text { (2019) [13] }\end{array}$ & $X$ & - & - & - & - \\
\hline $\begin{array}{l}\text { Croitor et al. } \\
\text { (2020) [12] }\end{array}$ & $\mathrm{X}$ & - & - & - & - \\
\hline
\end{tabular}

To address these shortcomings, we seek to bridge the gap in understanding how input control and self control affect complementors' behavioral intentions (i.e., continuance and switching intentions) on digital platforms. Moreover, we intend to shed light on why the effects of control mechanisms unfold. In sum, we investigate the following research question:

RQ: How and why do perceptions of input control and self control affect complementors' continuance and switching intentions on digital platforms?

To answer this research question, we conducted an online survey with 116 complementors from Kickstarter and Indiegogo, which are the two main reward-based crowdfunding platforms. Crowdfunding platforms are an established context to explore effects of control mechanisms on complementors and their complements
[48, 54], and thus is well-suited for our empirical investigation.

Our study makes several contributions to IS research and practice. First, we contribute to IS control literature by extending knowledge on the effects of input control and self control on digital platforms. Second, our study contributes to a more nuanced understanding of factors that explain complementors' behavioral intentions. Third, through the use of goal attainment theory, we shed light on factors through which the effects of control mechanisms unfold on digital platforms (i.e., perceived usefulness, perceived effort and satisfaction). In terms of practical contributions, our research offers platform providers valuable insights on how their control mechanisms affect complementors' perceptions and thus their willingness to stay on and keep contributing to digital platforms, thereby nurturing platform health and sustainability.

\section{Theoretical background}

\subsection{Digital platforms}

Consistent with previous studies in IS and strategic management research we refer to digital platforms as infrastructure that mediates interactions between complementors and end-users [17, 18, 37]. Complementors, as the focus of our research, are external parties that supply complements to the platform ecosystem, but are not directly related to the platform provider [55]. End-users, on the other hand, are individuals that use complements available in the platform ecosystem [41]. For example, while Kickstarter and Indiegogo enable transactions by connecting project creators and backers, Steam links game developers with players. Platform providers design, develop, and govern the platform and thereby manage interactions between complementors and endusers.

Cross-side network effects play a crucial role in the sustainability of digital platforms, as they drive the evolution and growth of digital platforms. Specifically, the more complementors provide complements, the more end-users access the respective digital platform [48]. In this regard, maintaining attractiveness for complementors is an important aspect for digital platforms to succeed in today's dynamic environment [4]. In order to increase complementors' intention to keep contributing to the platform and to decrease complementors' intention to leave the platform, platform providers exercise various forms of control mechanisms. 


\subsection{Control mechanisms}

Control mechanisms represent the most important part of platform governance [56] and are essential for platform success [20]. Control mechanisms enable platform providers to align their interests and strategies with those of the complementors. IS Control literature makes an explicit distinction between formal and informal control mechanisms [33, 40, 56].

Formal control mechanisms (i.e., input, behavior and output control) are enforced by platform providers through specification and evaluation [8]. In terms of input control, platform providers use specified gatekeeping and screening procedures to decide which complementors and complements are allowed to enter the respective platform [13]. In terms of behavioral control, platform providers evaluate complementors' behaviors on a digital platform to guide them toward desired outcomes. In contrast, under output control, complementors' performance targets are pre-specified as objectives, which are then evaluated, rewarded or punished by a platform provider.

Informal control mechanisms (i.e., clan and self control), on the other hand, are built on meanings of self-regulation or shared norms and values of groups or individuals [56]. Self control occurs when platform providers encourage complementors to exercise selfregulation by providing tools for self-management and by structuring the platform environment appropriately [40]. In contrast, clan control occurs when complementors' behavior is motivated by shared norms and values among groups with a common goal [40].

Both formal and informal control mechanisms have been studied in the context of digital platforms and have been proven to be effective governance mechanisms for platform providers to align their interests and strategies with those of the complementors. However, our understanding of the effects of the combination of different control mechanisms (i.e., input control and self control) is still limited. To understand why perception of input control and self control affect complementors' behavioral intentions, we examine how these control mechanisms influence complementors' satisfaction as an important antecedent to complementors' behavioral intentions.

\subsection{Goal attainment theory}

In this section, we draw upon goal attainment theory $[7,44]$ as the theoretical underpinning to develop our research model. Goal attainment theory [7, 44] posits that individuals' satisfaction of attaining a certain goal is determined not solely based on what they gain, but according to the tradeoff between perceived benefits and perceived costs. Specifically, the goal attainment theory postulates the mediating role of perceived net goal attainment between perceived benefits, perceived costs and satisfaction. As such, the theory posits that perceived benefits and costs influence satisfaction not directly but through net goal attainment as the trade-off between these two aspects, which means that high levels of perceived benefits are not necessarily related to high levels of satisfaction. Likewise, high levels of perceived costs are not necessarily related to low levels of satisfaction. Goal attainment theory is usually accompanied by a cost-benefit framework [7]. Within this framework, positive factors affecting perceived net goal attainment are considered benefits, whereas negative factors are considered costs. In our study, we conceptualize perceived usefulness as the benefit factor and perceived effort as the cost factor.

\section{Research model and hypotheses}

In this section, we draw on goal attainment theory $[7,44]$ as the theoretical underpinning to develop our research model, as presented in Figure 1. In this model, perceived costs (i.e., perceived effort) and perceived benefits (i.e., perceived usefulness) are considered antecedents of perceived net goal attainment, which in turn influences complementors' satisfaction.

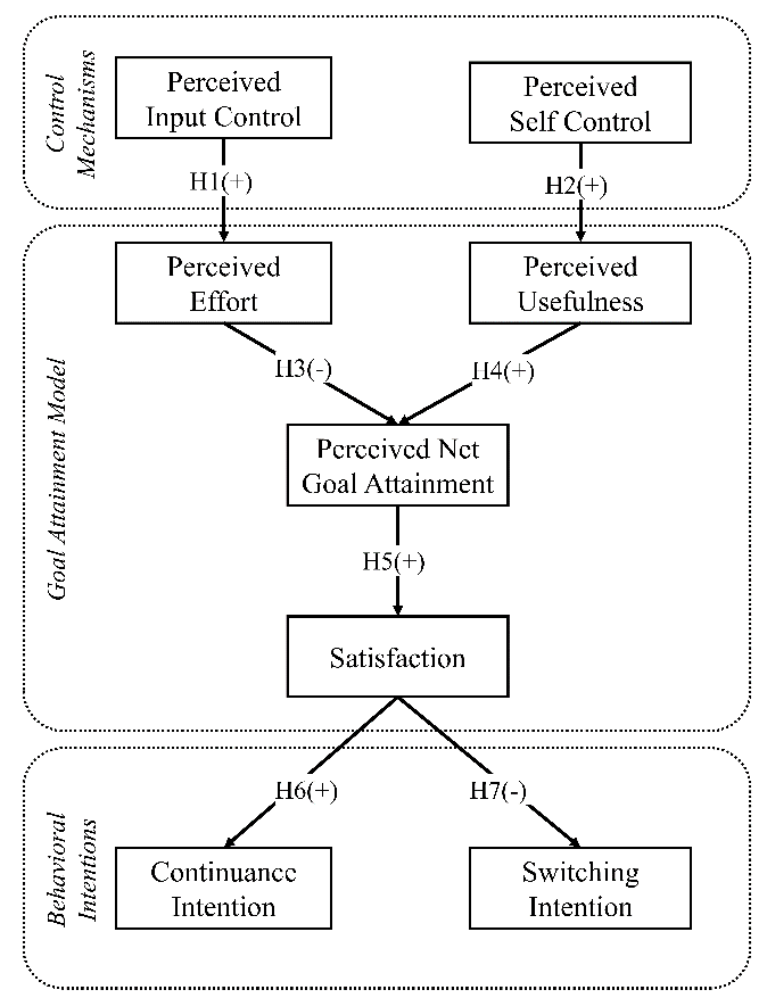

Figure 1. Research model. 
We propose that perceived input control has a positive effect on perceived effort (H1) and perceived self control has a positive effect on perceived usefulness (H2). Furthermore, we propose that perceived effort has a negative effect on perceived net goal attainment (H3), whereas perceived usefulness has a positive effect on perceived net goal attainment (H4). We also propose that perceived net goal attainment positively influences satisfaction (H5). Lastly, we posit that satisfaction has a positive effect on continuance intention (H6) and a negative effect on switching intention $(\mathrm{H} 7)$.

In the context of digital platforms, perceived effort is defined as the extent to which complementors believe providing a complement to a digital platform is associated with effort (adapted from [52]). Complementors must fulfill requirements to provide sufficient information for the platform providers to individually decide whether or not to allow the submitted complement to enter the digital platform [13, 49]. Both the collection as well as the submission of such information requires effort by the complementor. The higher the level of input control, the higher we expect the quantity and quality of information required, causing effort to rise. Thus, we hypothesize:

H1: Perceived input control has a positive effect on complementors' perceived effort.

We refer to perceived usefulness as the extent to which a platform is perceived as useful by complementors for their activities (adapted from [14]). Self control enables complementors to set their own goals and to regulate themselves concerning their activities. In this regard, complementors' perceptions of self-regulation have been found to relate to higher intrinsic motivation, perceived usefulness and satisfaction [16, 42]. If complementors provide complements to a platform which supports complementors' self-interests and self-regulation, they are more likely to perceive the platform as useful for their activities. Therefore, we hypothesize:

H2: Perceived self control has a positive effect on complementors' perceived usefulness.

According to goal attainment theory, costs reduce individuals' perceived net goal attainment $[7,44]$. In the context of digital platforms, complementors are confronted with costs in the form of effort to fulfill the platforms' requirements. Accordingly, the higher complementors' perceived effort is, the lower is their perceived net goal attainment, as higher effort is an obstacle for complementors to fulfill their objectives on the platform. Hence, we hypothesize:

H3: Perceived effort has a negative effect on complementors' perceived net goal attainment.
Goal attainment theory also posits that benefits increase individuals' perceived net goal attainment [7, 44]. In the context of digital platforms, benefits relate to complementors' perception of the usefulness of the platform. Accordingly, the higher complementors' perceived usefulness is, the higher is their perceived net goal attainment, as higher usefulness aids complementors in their objectives on the platform. Thus, we hypothesize:

H4: Perceived usefulness has a positive effect on complementors' perceived net goal attainment.

A key proposition of goal attainment theory is that perceived net goal attainment determines individuals' satisfaction [46]. Satisfaction refers to complementors' evaluation and affective response to the overall experience with the platform (adapted from [39]). Previous studies have empirically shown this positive effect on individuals' satisfaction in different settings [7, 44]. Applied to the context of digital platforms, the higher complementors' perceived net goal attainment is, the more satisfied do they feel using a digital platform, as a more positive balance between costs and benefits improves complementors' experience with the platform. Therefore, we hypothesize:

H5: Perceived net goal attainment has a positive effect on complementors' satisfaction.

In the context of digital platforms, continuance intention refers to complementors' intention to keep contributing complements to a respective digital platform (adapted from [5]). Previous studies have shown that complementors' satisfaction is a decisive predictor of their continuance intention [12, 32]. Consequently, we suggest that complementors' satisfaction with a digital platform leads to higher continuance intentions. Hence, we hypothesize:

H6: Satisfaction has a positive effect on complementors' continuance intentions.

We refer to complementors' switching intentions as complementors' intentions to stop contributing complements to the current platform and their simultaneous intention to instead provide their complements to other (rival) platforms (adapted from [2]). Previous studies have shown that dissatisfaction, which refers to individuals' state of not being satisfied, has a positive effect on individuals' switching intentions [47]. Accordingly, we suggest that complementors' satisfaction with a digital platform leads to lower switching intentions. Thus, we hypothesize:

H7: Satisfaction has a negative effect on complementors' switching intentions. 


\section{Methodology}

Our empirical setting comprises two major rewardbased crowdfunding platforms, Kickstarter and Indiegogo. Generally, reward-based crowdfunding is used for creative projects [54]. On Kickstarter and Indiegogo, project creators collect monetary support from backers all over the world by offering different forms of reward [53] (e.g., future product, usually with a discount in price or early delivery). Kickstarter employs the so-called "all or nothing" business model, in which a minimum campaign goal is specified, and a limited time period is given to achieve this goal. The project creator receives the funds pledged to his or her project only if the specified amount is reached within the respective time period. Indiegogo, on the other hand, allows project creators to choose between "all or nothing" and "flexible funding". Flexible funding enables project creators to receive the pledged funds that they accumulated throughout the duration of the project even if the project has failed (i.e., does not reach the specified amount within the predefined time period).

Kickstarter and Indiegogo offer ideal settings for our empirical analyses for several reasons: First, reward-based crowdfunding platforms are typical digital platforms with complementors (i.e., project creators) offering complements (i.e., projects) to endusers (i.e., backers). Second, since the policy change in June 2014 on Kickstarter (i.e., removal of manual evaluation that was mandatory for each project) [54], both platforms apply similar input and self control mechanisms, allowing to investigate both digital platforms from the complementors' perspective at the same time. Finally, during the past few years, over $1,200,000$ total projects were submitted on Kickstarter and Indiegogo, which enabled project creators to collect billions of dollars.

\subsection{Data collection and sample description}

To test our research model, we developed and conducted an online survey addressing complementors on Kickstarter and Indiegogo over a period of two months. Complementors were contacted via chat forums and social media channels, such as Facebook and Reddit. As an incentive, we assured to fund the planting of a tree for every completed survey. After removing five cases due to an implausibly short response time (less than 100 seconds compared to an overall mean of 257 seconds), we received 116 valid responses. The majority of our respondents were project creators on Kickstarter $(67.2 \%)$, whereas the rest was using Indiegogo (32.8\%). Sample demographics are presented in Table 2.
Table 2. Sample demographics $(\mathrm{N}=116)$.

\begin{tabular}{|l|l|c|}
\hline Item & Category & $\%$ \\
\hline Gender & Male & 70.7 \\
& Female & 29.3 \\
\hline Age & $18-24$ & 8.6 \\
& $25-34$ & 35.3 \\
& $35-44$ & 25.0 \\
& $45-54$ & 17.2 \\
& $55+$ & 13.8 \\
\hline Education & No schooling completed & 1.7 \\
& High school graduate & 25.0 \\
& Bachelor's degree & 37.1 \\
& Master's degree & 31.9 \\
& Doctorate degree & 4.3 \\
\hline Country & United States & 32.8 \\
& Germany & 11.2 \\
& United Kingdom & 10.3 \\
& Other & 45.7 \\
\hline
\end{tabular}

As we collected self-reported data from a single data source, common method bias might be a potential concern. We performed several steps to reduce any common method bias that might arise [43]. First, we informed all respondents that their answers would be anonymous, that there were no right or wrong answers, and that responses would be used solely for research purposes. Second, we also employed the markervariable technique [36] and included a marker-variable (blue attitude) in our survey. This variable did not create any significant change in the variance explained in the dependent variables. These procedures gave us confidence that common method bias is not a major concern in this study.

\subsection{Measurement}

All measures in our study were based on established scales from previous studies. Consistent with previous studies on digital platforms, we measured perceived input control (PIC) using three items [13], perceived self control (PSC) using three items [51], perceived effort (PE) using four items [52], perceived usefulness (PU) using four items [1], perceived net goal attainment (PNGA) using four items [46], satisfaction (SAT) using four items [5], continuance intention (CI) using three items [45], and switching intention (SI) using three items [35]. All items were measured on a 7-point Likerttype scale, ranging from 1 (strongly disagree) to 7 (strongly agree). The final questionnaire consisted of 28 items (see Table A1. in Appendix). In addition, we included control variables to account for alternative explanations. We measured complementors' gender, age, education, and country of residence (see Table 2). 


\section{Analysis and results}

We used structural equation modeling with partial least squares (PLS) using SmartPLS 3.2.8 to evaluate the measurement models and to test our research hypotheses [26]. Consistent with prior research using PLS models, we first assess our measurement model and then evaluate our structural model [28].

\subsection{Measurement model assessment}

Following guidelines of Bhattacherjee and Premkumar [6], we analyzed our constructs regarding convergent validity and discriminant validity. Convergent validity was evaluated using three criteria recommended by Fornell and Larcker [19] (see Table $3)$. First, the factor loadings of all items were above the threshold of 0.70 and significant $(p<0.001)$ [9]. Second, composite reliability (CR) of all constructs was above the threshold of 0.80 [3]. Lastly, average variance extracted (AVE) of all constructs was above 0.50 [25]. Hence, these results demonstrate that our measurement model has adequate convergent validity.

Table 3. Results of the convergent validity analysis.

\begin{tabular}{|c|c|c|c|c|}
\hline Constructs & Mean (SD) & $\begin{array}{c}\text { Factor } \\
\text { loadings }\end{array}$ & CR & AVE \\
\hline PIC & $3.65(1.61)$ & $0.82-0.93$ & 0.91 & 0.70 \\
\hline PSC & $5,81(1.42)$ & $0.83-0.84$ & 0.90 & 0.76 \\
\hline PE & $3.89(1.72)$ & $0.85-0.88$ & 0.92 & 0.75 \\
\hline PU & $5.18(1.61)$ & $0.83-0.88$ & 0.92 & 0.74 \\
\hline PNGA & $5.61(1.48)$ & $0.88-0.93$ & 0.95 & 0.84 \\
\hline SAT & $5.12(1.39)$ & $0.89-0.95$ & 0.95 & 0.84 \\
\hline CI & $5.47(1.70)$ & $0.93-0.96$ & 0.96 & 0.90 \\
\hline SI & $3.04(1.76)$ & $0.94-0.95$ & 0.96 & 0.90 \\
\hline
\end{tabular}

Discriminant validity describes the extent to which measurement constructs differ from one another [38] and can be tested using Heterotrait-Monotrait (HTMT) analysis. The highest HTMT value of 0.75 was between perceived usefulness and perceived net goal attainment (see Table 4). Since all values were below the recommended threshold of 0.90 [27], we conclude that our measurement model has good discriminant validity.

After establishing reliability and validity of the constructs, we continue with the assessment of our structural model, which involves examining the relationships between the constructs [26].
Table 4. Results of the discriminant validity analysis.

\begin{tabular}{|c|c|c|c|c|c|c|c|}
\hline & PIC & PSC & PE & PU & PNGA & SAT & CI \\
\hline PSC & 0.25 & & & & & & \\
\hline PE & 0.60 & 0.19 & & & & & \\
\hline PU & 0.16 & 0.13 & 0.10 & & & & \\
\hline PNGA & 0.10 & 0.16 & 0.21 & 0.75 & & & \\
\hline SAT & 0.17 & 0.08 & 0.10 & 0.66 & 0.65 & & \\
\hline CI & 0.10 & 0.24 & 0.27 & 0.55 & 0.60 & 0.56 & \\
\hline SI & 0.13 & 0.14 & 0.21 & 0.52 & 0.59 & 0.31 & 0.44 \\
\hline
\end{tabular}

\subsection{Structural model assessment}

The results of the structural model analysis, including standardized path coefficients and their statistical significance levels, are displayed in Figure 2. We first tested for alternative explanations by analyzing the effects of our control variables, but did not find any significant impact of gender, age, education or country of residence on complementors' continuance intention or switching intention (all $\mathrm{p}>0.05$ ).

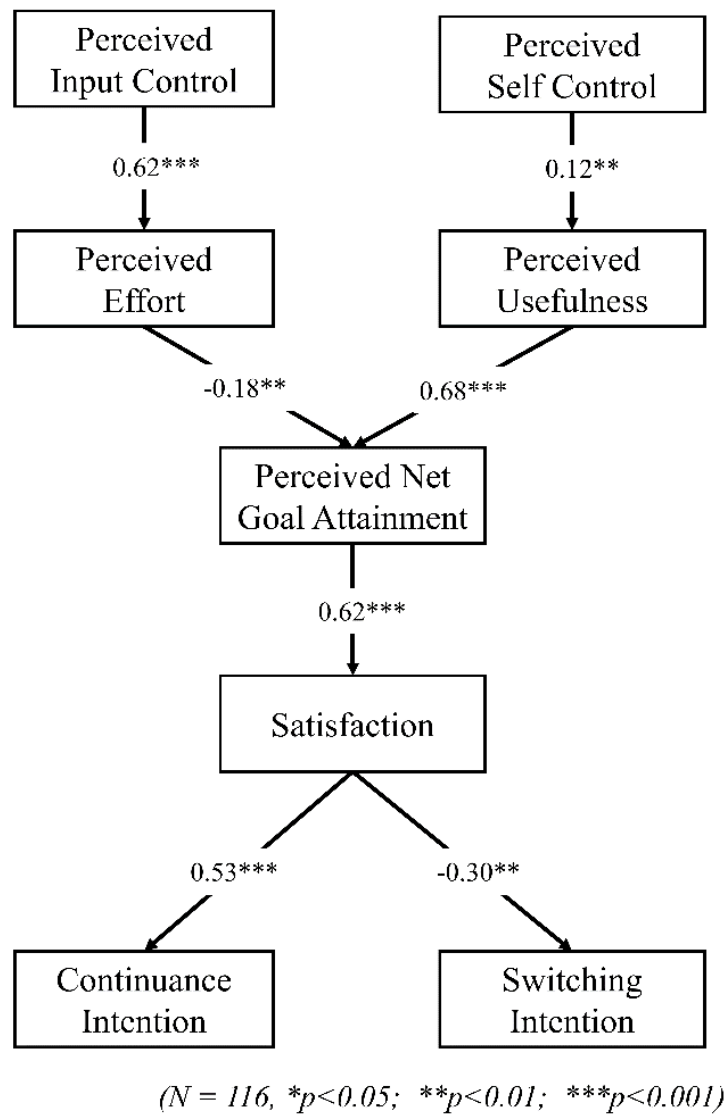

Figure 2. Model testing results. 
Based on the structural analysis, our model explained $39 \%$ of the variance in perceived effort, $34 \%$ of the variance in perceived usefulness, $51 \%$ of the variance in perceived net goal attainment, $38 \%$ of the variance in satisfaction, $28 \%$ of the variance in continuance intention, and $9 \%$ of the variance in switching intention.

Perceived input control had a positive significant effect on perceived effort $(\beta=0.62, p<0.001)$, supporting H1. Perceived self control had a positive significant effect on perceived usefulness $(\beta=0.12, p<$ 0.01), supporting H2. Furthermore, we also found a negative significant effect of perceived effort on perceived net goal attainment $(\beta=-0.18, \mathrm{p}<0.01)$ and a positive significant effect of perceived usefulness on perceived net goal attainment $(\beta=0.68, p<0.001)$, supporting $\mathrm{H3}$ and $\mathrm{H4}$. Perceived net goal attainment had a positive significant effect on satisfaction $(\beta=0.62$, $\mathrm{p}<0.001$ ), supporting H5. Finally, we found a positive significant effect of satisfaction on continuance intention $(\beta=0.53, p<0.001)$ and a negative significant effect of satisfaction on switching intention $(\beta=-0.30$, $\mathrm{p}<0.01$ ), supporting $\mathrm{H6}$ and $\mathrm{H7}$.

\section{Discussion}

The main objective of this study was to investigate whether and why perceptions of input control and self control affect complementors' intention to stay on and keep contributing complements to a platform. Four key findings can be derived from this study. First, we find that perceived input control increases complementors' perceived effort due to the collection and submission of information required by platform providers. Second, perceived self control increases complementors' perceived usefulness of a digital platform, as setting one's own goals aids complementors to regulate themselves and thus thrive on the platform. Third, perceived effort and perceived usefulness, the two opposing factors evaluated by complementors when interacting with the platform, jointly affect overall perceived net goal attainment. Lastly, consistent with previous studies [44, 46], we show that perceived net goal attainment exerts a positive impact on complementors' satisfaction, reflecting complementors' importance of attaining their goal. Furthermore, our study confirms the relationship between satisfaction and the behavioral intentions of continuance intention [12] and switching intention [34]. In summary, we demonstrate a link between perceptions of input control and self control mechanisms on complementors' continuance and switching intentions.

Our study makes several contributions to IS research and practice. First, we contribute to IS control literature by extending knowledge on the consequences of different control mechanisms. Specifically, we increase our understanding of control mechanisms by showing how perceived input control and perceived self control affect complementors' behavioral intentions on digital platforms. Second, whereas extent literature focuses primarily on the effects of control mechanisms on complementors' continuance intention (e.g., $[12,13$, 23]), we contribute by extending the research scope to complementors' switching intention, which is an equally important factor for a platform's success and sustainability [50]. A third contribution of this study relates to the explanation of why perceived input control and perceived self control affect complementors' behavioral intentions on digital platforms. By identifying perceived usefulness, perceived effort, and satisfaction as underlying variables, our study contributes to a more nuanced understanding of factors that explain complementors' behavioral intentions.

In terms of practical contributions, our research offers platform providers valuable insights on how their control mechanisms affect complementors' perceptions and thus their willingness to stay on and keep contributing to digital platforms. Whereas input control deters complementors' participation, platform providers can apply intensified self control to increase complementors' continuance intention and thereby nurture platform health and sustainability.

Despite valuable contributions, our study has some limitations which provide opportunities for future research. First, our study was conducted in the context of reward-based crowdfunding platforms. We call for future studies to replicate our findings in other platform contexts to confirm generalizability. Second, in our study, we focused only on input and self control mechanisms. Future studies may extend this article's model by including and comparing perceptions of further types of control mechanisms (e.g., behavior, output and clan control). Finally, we measured complementors' behavioral intentions rather than actual behaviors. However, prior studies have shown that behavioral intentions correlate with actual behaviors [52]. Therefore, measuring continuance and switching intentions may provide adequate indication of complementors' actual behaviors. In conclusion, we believe that our study offers unique insights into the various effects and dynamics a platform provider can evoke when managing control mechanisms.

\section{Acknowledgments}

This research was funded by the German Research Foundation (DFG) under grant numbers BE 4308/3-1 and BE 4308/3-2. 


\section{References}

[1] Agarwal, R., Karahanna, E., "Time Flies When You're Having Fun: Cognitive Absorption and Beliefs about Information Technology Usage", MIS Quarterly, 24 (4), 2000, pp. 665-694.

[2] Antón, C., Camarero, C., Carrero, M., "The mediating effect of satisfaction on consumers' switching intention", Psychology \& Marketing, 24 (6), 2007, pp. 511-538.

[3] Bagozzi, R.P., Yi, Y., "On the evaluation of structural equation models", Journal of the Academy of Marketing Science, 16 (1), 1988, pp. 74-94.

[4] Benlian, A., Hilkert, D., Hess, T., "How open is this platform? The meaning and measurement of platform openness from the complementors' perspective", Journal of Information Technology, 30 (3), 2015, pp. 209-228.

[5] Bhattacherjee, A., "Understanding Information Systems Continuance: An Expectation-Confirmation Model", MIS Quarterly, 25 (3), 2001, pp. 351-370.

[6] Bhattacherjee, A., Premkumar, G., "Understanding Changes in Belief and Attitude toward Information Technology Usage: A Theoretical Model and Longitudinal Test", MIS Quarterly, 28 (2), 2004, pp. 229-254.

[7] Briggs, R.O., Reinig, B.A., de Vreede, G.-J., "Meeting Satisfaction for Technology-Supported Groups:An Empirical Validation of a Goal-Attainment Model", Small Group Research, 37 (6), 2006, pp. 585-611.

[8] Cardinal, L.B., Sitkin, S.B., Long, C.P., "Balancing and Rebalancing in the Creation and Evolution of Organizational Control", Organization Science, 15 (4), 2004, pp. 411-431.

[9] Carmines, E., Zeller, R., Reliability and Validity Assessment, (SAGE Publishing, Beverly Hills, CA), 1979.

[10] Choudhury, V., Sabherwal, R., "Portfolios of Control in Outsourced Software Development Projects", Information Systems Research, 14 (3), 2003, pp. 291314.

[11] Constantinides, P., Henfridsson, O., Parker, G.G., "Introduction - Platforms and Infrastructures in the Digital Age", Information Systems Journal, 29 (2), 2018, pp. 381-400.

[12] Croitor, E., Adam, M., Benlian, A., "Perceived Input Control on Digital Platforms: A Mixed-Methods Investigation of Web-Browser Platforms", Journal of Decision Systems, 2020, pp. 1-22.

[13] Croitor, E., Benlian, A., "Perceived Input Control on Online Platforms from the Application Developer Perspective: Conceptualization and Scale Development", Journal of Decision Systems, 28 (1), 2019, pp. 19-40.

[14] Davis, F.D., "Perceived Usefulness, Perceived Ease of Use, and User Acceptance of Information Technology", MIS Quarterly, 13 (3), 1989, pp. 319-340.

[15] de Reuver, M., Bouwman, H., "Governance mechanisms for mobile service innovation in value networks", Journal of Business Research, 65 (3), 2012, pp. 347-354.
[16] Deci, E.L., Ryan, R.M., Handbook of SelfDetermination Research, in, (University of Rochester Press, Rochester, NY, 2002).

[17] Eisenmann, T., Parker, G., Van Alstyne, M., "Platform envelopment", Strategic Management Journal 32 (12), 2011, pp. 1270-1285.

[18] Foerderer, J., Kude, T., Schuetz, S.W., Heinzl, A., "Knowledge boundaries in enterprise software platform development: Antecedents and consequences for platform governance", Information Systems Journal, 29 (1), 2018, pp. 119-144.

[19] Fornell, C., Larcker, D.F., "Evaluating Structural Equation Models with Unobservable Variables and Measurement Error", Journal of Marketing Research, 18 (1), 1981, pp. 39-50.

[20] Ghazawneh, A., Henfridsson, O., "Balancing platform control and external contribution in third-party development: the boundary resources model", Information Systems Journal, 23 (2), 2013, pp. 173192.

[21] Goldbach, T., Benlian, A., "How Social Capital Facilitates Clan Control on Software Platforms to Enhance App-Developers' Performance and Success", Proceedings of the 36th International Conference on Information Systems, 2015, Fort Worth, Texas, USA.

[22] Goldbach, T., Benlian, A., "Understanding Informal Control Modes on Software Platforms - The Mediating Role of Third-Party Developers' Intrinsic Motivation", Proceedings of the 36th International Conference on Information Systems, 2015, Fort Worth, USA.

[23] Goldbach, T., Benlian, A., Buxmann, P., "Differential effects of formal and self-control in mobile platform ecosystems: Multi-method findings on third-party developers' continuance intentions and application quality", Information \& Management, 55 (3), 2018, pp. 271-284.

[24] Goldbach, T., Kemper, V., Benlian, A., "Mobile Application Quality and Platform Stickiness under Formal vs. Self-Control - Evidence from an Experimental Study", Proceedings of the 35th International Conference on Information Systems, 2014, Auckland, New Zealand.

[25] Gounaris, S., Dimitriadis, S., "Assessing service quality on the Web: evidence from business-to-consumer portals", Journal of Services Marketing, 17 (5), 2003, pp. 529-548.

[26] Hair, F., Sarstedt, M., Hopkins, L., Kuppelwieser, V., "Partial least squares structural equation modeling (PLS-SEM)", European Business Review, 26 (2), 2014, pp. 106-121.

[27] Henseler, J., Ringle, C.M., Sarstedt, M., "A new criterion for assessing discriminant validity in variancebased structural equation modeling", Journal of the Academy of Marketing Science, 43 (1), 2015, pp. 115135.

[28] Hulland, J., "Use of partial least squares (PLS) in strategic management research: a review of four recent studies", Strategic Management Journal, 20 (2), 1999, pp. 195-204. 
[29] Indiegogo, "Number of projects on Indiegogo", https://www.indiegogo.com/, (retrieved 31 Mai, 2020).

[30] Kickstarter, "Number of projects on Kickstarter", https://www.kickstarter.com, (retrieved 31 Mai, 2020).

[31] Kickstarter, "Prohibited Items", https://www.kickstarter.com/rules/prohibited, (retrieved 31 Mai, 2020).

[32] Kim, H.J., Kim, I., Lee, H., "Third-party mobile app developers' continued participation in platform-centric ecosystems: An empirical investigation of two different mechanisms", International Journal of Information Management, 36 (1), 2016, pp. 44-59.

[33] Kirsch, L.J., "Portfolios of Control Modes and IS Project Management", Information Systems Research, 8 (3), 1997, pp. 215-239.

[34] Liang, L.J., Choi, H.C., Joppe, M., "Exploring the relationship between satisfaction, trust and switching intention, repurchase intention in the context of Airbnb", International Journal of Hospitality Management, 69 2018, pp. 41-48.

[35] Lin, T.-C., Cheng, H.K., Wang, F.-S., Chang, K.-J., "A Study of Online Auction Sellers' Intention to Switch Platform: The Case of Yahoo!Kimo Versus Ruten_eBay*", Decision Sciences, 43 (2), 2012, pp. 241-272.

[36] Malhotra, N.K., Kim, S.S., Patil, A., "Common Method Variance in IS Research: A Comparison of Alternative Approaches and a Reanalysis of Past Research", Management Science, 52 (12), 2006, pp. 1865-1883.

[37] McIntyre, D.P., Srinivasan, A., "Networks, platforms, and strategy: Emerging views and next steps", Strategic Management Journal, 38 (1), 2017, pp. 141-160.

[38] O'Leary-Kelly, S.W., J. Vokurka, R., "The empirical assessment of construct validity", Journal of Operations Management, 16 (4), 1998, pp. 387-405.

[39] Oliver, R.L., "A Cognitive Model of the Antecedents and Consequences of Satisfaction Decisions", Journal of Marketing Research, 17 (4), 1980, pp. 460-469.

[40] Ouchi, W.G., "A Conceptual Framework for the Design of Organizational Control Mechanisms", Management Science, 25 (9), 1979, pp. 833-848.

[41] Parker, G., Alstyne, M.V., Jiang, X., "Platform Ecosystems: How Developers Invert the Firm", MIS Quarterly, 41 (1), 2017, pp. 255-266.

[42] Pearce Craig, L., Sims Henry, P., Cox Jonathan, F., Ball, G., Schnell, E., Smith Ken, A., Trevino, L., "Transactors, transformers and beyond: A multimethod development of a theoretical typology of leadership", Journal of Management Development, 22 (4), 2003, pp. 273-307.

[43] Podsakoff, P.M., MacKenzie, S.B., Lee, J.-Y., Podsakoff, N.P., "Common method biases in behavioral research: A critical review of the literature and recommended remedies", Journal of Applied Psychology, 88 (5), 2003, pp. 879-903.

[44] Reinig, B., A., "Toward an Understanding of Satisfaction with the Process and Outcomes of Teamwork", Journal of Management Information Systems, 19 (4), 2003, pp. 65-83.

[45] Schlosser, A.E., White, T.B., Lloyd, S.M., "Converting Web Site Visitors into Buyers: How Web Site
Investment Increases Consumer Trusting Beliefs and Online Purchase Intentions", Journal of Marketing, 70 (2), 2006, pp. 133-148.

[46] Sun, Y., Fang, Y., Lim, K.H., "Understanding knowledge contributors' satisfaction in transactional virtual communities: A cost-benefit trade-off perspective", Information \& Management, 51 (4), 2014, pp. 441-450.

[47] Tang, Z., Chen, L., Gillenson, M.L., "Understanding brand fan page followers' discontinuance motivations: A mixed-method study", Information \& Management, 56 (1), 2019, pp. 94-108.

[48] Thies, F., Wessel, M., Benlian, A., "Network effects on crowdfunding platforms: Exploring the implications of relaxing input control", Information Systems Journal, 28 (6), 2018, pp. 1239-1262.

[49] Tiwana, A., "Evolutionary Competition in Platform Ecosystems", Information Systems Research, 26 (2), 2015, pp. 266-281.

[50] Tiwana, A., "Platform Desertion by App Developers", Journal of Management Information Systems, 32 (4), 2015, pp. 40-77.

[51] Tiwana, A., Keil, M., "Control in Internal and Outsourced Software Projects", Journal of Management Information Systems, 26 (3), 2009, pp. 944.

[52] Venkatesh, V., Thong, J.Y.L., Xu, X., "Consumer Acceptance and Use of Information Technology: Extending the Unified Theory of Acceptance and Use of Technology", MIS Quarterly, 36 (1), 2012, pp. 157178 .

[53] Wessel, M., Adam, M., Benlian, A., "The impact of sold-out early birds on option selection in reward-based crowdfunding", Decision Support Systems, 1172019 , pp. 48-61.

[54] Wessel, M., Thies, F., Benlian, A., "Opening the floodgates: the implications of increasing platform openness in crowdfunding", Journal of Information Technology, 32 (4), 2017, pp. 344-360.

[55] Wiener, M., Cram, A., Benlian, A., TechnologyMediated Control Legitimacy in the Gig Economy: Conceptualization and Nomological Network, in: A.H. Rudy Hirschheim, Jens Dibbern Ed. Information Systems Outsourcing: The Era of Digital Transformation (5th Edition), (Springer, Berlin Heidelberg, 2020).

[56] Wiener, M., Mähring, M., Remus, U., Saunders, C., "Control Configuration and Control Enactment in Information Systems Projects: Review and Expanded Theoretical Framework", MIS Quarterly, 40 (3), 2016, pp. 741-774. 


\section{Appendix}

Table A1. Construct measures.

\begin{tabular}{|l|}
\hline Perceived Input Control (PIC) [13] \\
(PIC1) It is burdensome for me to comply with all \\
requirements to publish campaigns on the crowdfunding \\
platform. \\
(PIC2) Overall, the crowdfunding platform sets strict \\
formal criteria for publication approval. \\
(PIC3) Publishing campaigns on the crowdfunding \\
platform is subject to stringent screening processes. \\
(PIC4) In my opinion, it is hard to publish campaigns on \\
the crowdfunding platform.
\end{tabular}

\section{Perceived Self Control (PSC) [51]}

(PSC1) I self-manage my campaign activities on the crowdfunding platform.

(PSC2) I set specific goals for my campaigns without involvement of the crowdfunding platform.

(PSC3) I define specific procedures for my campaign activities without involvement of the crowdfunding platform.

Perceived Effort (PE) [52]

(PE1) When publishing a campaign on the crowdfunding platform, complying with the publication requirements is time consuming for me.

(PE2) When publishing a campaign on the crowdfunding platform, complying with the publication requirements is burdensome for me.

(PE3) When publishing a campaign on the crowdfunding platform, complying with the publication requirements is costly for me.

(PE4) When publishing a campaign on the crowdfunding platform, complying with the publication requirements is effortful for me.

Perceived Usefulness (PU) [1]

(PU1) I am sure the crowdfunding platform is able to help me get funds for my campaigns.

(PU2) The crowdfunding platform helps me to raise funds for my campaigns.

(PU3) The crowdfunding platform increases my productivity in obtaining funds for my campaigns.

(PU4) Using the crowdfunding platform increases my chances of getting funds for my campaigns.
Perceived Net Goal Attainment (PNGA) [46]

(PNGA1) Publishing on the crowdfunding platform is worth the effort that I put in.

(PNGA2) The things that I accomplish with publishing my campaigns on the crowdfunding platform warrant my effort.

(PNGA3) The results of publishing my campaigns on the crowdfunding platform are worth the time I invest.

(PNGA4) The value I receive from the published campaigns on the crowdfunding platform justifies my efforts.

Satisfaction (SAT) [5]

(SAT1) When publishing a campaign on the crowdfunding platform, I find my experience to be interesting.

(SAT2) When publishing a campaign on the crowdfunding platform, I find my experience to be enjoyable.

(SAT3) When publishing a campaign on the crowdfunding platform, I find my experience to be fun.

Continuance Intention (CI) [45]

(CI1) It's likely that I would publish another campaign on the crowdfunding platform.

(CI2) It's possible that I would publish another campaign on the crowdfunding platform.

(CI3) It's probable that I would publish another campaign on the crowdfunding platform.

Switching Intention (SI) [35]

(SI1) I intend to switch to other (rival) platforms in the near future.

(SI2) I plan to switch to other (rival) platforms in the near future.

(SI3) I predict I will switch to other (rival) platforms in the near future. 